\section{Intracellular Modifications in the Pancreas during Secretion}

During secretion, cells undergo well-known cytological and biochemical modifications. The cytological changes manifest themselves first in the formation of ergastoplasm in the cytoplasm, and secondly within the secretion granula, the secretion granula disappearing during the secreting cycle ${ }^{\mathbf{1}}$. Biochemically, the most important modification is the great diminution and the synthesis of the exocellular enzymes during the secretion period ${ }^{2}$. Recently, the importance of the different cellular fractions in protein synthesis has been much discussed, and I have studied the modifications of the protein content in the cellular fractions separated from the normal and the secreting pancreas.

Two groups of ten albino Wistar rats of weight 100-120 gm. were injected intramuscularly with $1.5 \mathrm{ml}$. of 0.85 per cent sodium chloride or with $1.5 \mathrm{ml}$. of 0.2 per cent pylocarpine dissolved in 0.85 per cent sodium chloride. After two hours, the rats were killed and bled, and the pancreases were homogenized with two volumes of isotonic sucrose. From these homogenates the nuclei were separated by centrifuging at $600 \mathrm{~g}$, the secretion granula at $1,000 \mathrm{~g}$, as prescribed by Hokin ${ }^{3}$, the mitochondria at $2,400 \mathrm{~g}$.

The amount of protein present in each pellet and in the supernatant solution was determined by the biuret method. 'There was no difference between the content of total proteins in the normal and in the secreting pancreas. The percentage of the protein contained in the various cell fractions was calculated with respect to total cell protein.

It is seen from the results reported here that after injection of pylocarpine a large part of the nuclear proteins (approximately 30 per cent) and of the secretion granula (approximately 50 per. cent) dis-

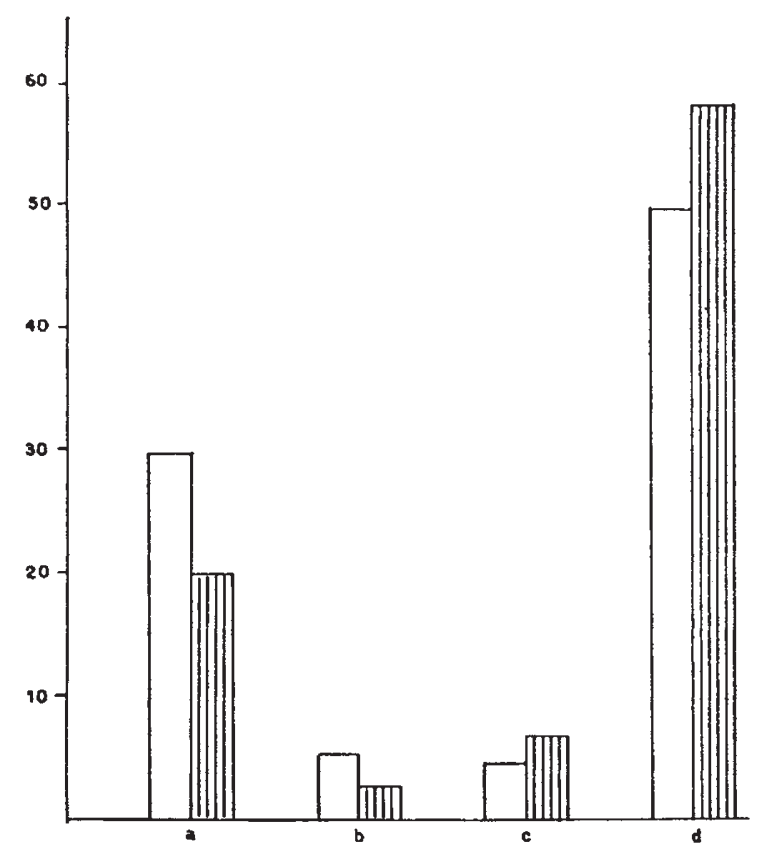

Fig. 1. Protein distribution (as a percentage) in the different cellular fractions of normal (open column) and secreting pancreas (shaded column): $(a)$ nuclei, $(b)$ granula, $(c)$ appear. At the same time, there is an augmentation of the mitochondrial, microsomial and soluble proteins. The lowering of nuclear and secretion granula proteins agrees with the observations of Lang et al. ${ }^{5}$ and Hokin ${ }^{3}$, who found a great concentration of the exocellular enzymes in these two cellular fractions. It is therefore reasonable to expect that during the secretion of the pancreatic exocellular enzymes these fractions lose a part of their normal protein content. The simultaneous increase of the protein content of the other two fractions studied (mitochondria and microsome soluble fraction) shows that also in the synthesis of pancreatic proteins the cytoplasma (particularly the microsome soluble fraction) is of great importance for the initial protein synthesis, as Zamecnick reported for the liver ${ }^{8}$.

The lowering of the exocellular enzyme content during panereatic secretion is not accompanied by simultaneous lowering of the protein content. From this observation Daly and Mirsky ${ }^{2}$ suggested that the pancreatic enzymes are not synthesized directly from the free amino-acids but from a proteic precursor; and this precursor, which probably accumulates during pancreatic secretion, keeps the total protein content in the cell unchanged. 'The results reported here are in support of Mirsky's hypothesis; in addition, they show also that the hypothetical proteic precursor is formed, if anywhere, in the microsome soluble cytoplasm fraction, whence it passes into the nuclei and secretion granula to form exocellular enzymes.

Institute of General Physiology,

R. RENDI Rome.

1 Ries, E., and Gersch, M., "Biologie der Zelle", 318 (1953).

Daly, M. M., and Mirsky, A. E., J. Cen. Physiol., 36, 243 (1952).

3 Hokin, L. E., Biochim. Biophys. Acta, 18, 379 (1955).

- Gornall, A. G., Bardawill, C. J., and David, M. M., J. Biol. Chem., 177, 751 (i949).

- Lang, K., Siebert, G., and Fischer, F., Biochem. Z., 324, 1 (1953).

- Zamecnick, P. C., Keller, E. B., Hoagland, M. B., and Littlefield, J. W., J. Cell.' Comp. Physiol., 47, Supp. 1 (1956).

\section{Effect of Injection of Organic Phosphates on Some Phosphorus Fractions in the Heart Muscle of Rats treated with Thyroxine}

THYroxine can uncouple oxidation and phosphorylation in animal tissues ${ }^{1}$, and it has been shown that this phenomenon occurs in the heart muscle of hyperthyroid animals, where a depression in adenosine triphosphate, phosphocreatine and inorganic phosphorus content is observed ${ }^{2}$. We have investigated the effects of injecting certain compounds concerned with phosphorylation on the levels of these substances in the heart muscle of rats treated with thyroxine.

Six groups of rats were used (mean weight about $115 \mathrm{gm}$.$) , and all except the normal control group$ $A$ were injected intramuscularly every day with $0.01 \mathrm{mgm}$. DL-thyroxine. In addition, the rats in four of the groups (animals of groups $C, D, E$ and $F$ of Table 1) were injected intraperitoneally every day with buffered physiological solutions of the following, respectively: $C, 0 \cdot 1 \mathrm{mgm}$. of adenosine triphosphate (sodium salt, Richter); $D, 0.5 \mathrm{mgm}$. cocarboxylase; $E, 5$ mgm. glucose-1-phosphute (sodium salt); $F, 5 \mathrm{mgm}$. fructose-1 : 6-diphosphate (calcium salt). The solutions were freshly prepared from dry material just before each injection. 